\title{
Hydrological effects of vegetation on slope stability
}

\author{
Brunella Balzano $^{1}$, Alessia Amabile ${ }^{1}$, Marco Caruso $^{2}$, Alessandro Tarantino ${ }^{1}$ \\ ${ }^{1}$ Department of Civil and Environmental Engineering, University of Strathclyde, Glasgow, UK \\ ${ }^{2}$ Dipartimento di Ingegneria Strutturale, Politecnico di Milano, Milano, Italy
}

\begin{abstract}
Vegetation controls the stability of slopes hydrologically by regulating suction in the slope. It is commonly assumed that vegetation 'extracts' soil water and therefore plays a beneficial role in stabilising the slope. This is a misconception because water removal by evaporation takes place even in the absence of vegetation. In other words, soil water is not removed by the plant but it is removed 'through the plant' by the atmosphere, the atmosphere being the driver of evaporation even in the case of bare soil.This paper is a contribution to the long debated question about the effectiveness of vegetation in controlling slope stability hydrologically. By considering the case of an infinite slope, the hydrological effects of vegetation on slope stability are assessed by comparing the vegetated slope with the bare one. The role of vegetation is analysed by considering two different soils (a silty sand and a silt), and various
\end{abstract}

- potential evapotranspiration regimes

- root depths and densities

- vulnerabilities to xylem cavitation

It is shown that vegetation can have an adverse 'hydrological' effect on stability under certain circumstances.

KEYWORDS: numerical modelling, suction, vegetation, unsaturated soils.

\section{INTRODUCTION}

Soil, plant, and atmosphere taken together form a physically integrated, dynamic system, which has been called the soil-plant-atmosphere continuum (SPAC) by Philip (1966). In this system, water flow takes place from regions of higher to regions of lower water potential $h$.

When a plant loses water to the atmosphere, the potential of water in the leaf drops at the sites of evaporation. A gradient in water potential is formed that drives water from the soil through the plant.

When water is available, evapotranspiration occurs at its maximum rate, defined by the potential evapotranspiration. As the drying power of the air is increased, the suction at the soil surface increases, and the rate at which water moves upward and evaporates increases accordingly. But eventually a limit is approached beyond which ET can no longer increase. Evapotranspiration is then controlled by the ability of the system to transmit water, regardless of the drying power of the atmosphere. It is therefore said to be in water limited regime.

An analytical method to derive the value of the limiting evapotranspiration in the bulk soil, at the soil-root interface and in the plant system is described in Amabile et al.

This method is applied in this paper in order to develop a slope stability analysis, taking into account vegetation effects by comparinson with the behaviour of bare soil under the same conditions.

\section{THE SLOPE MODEL}

Shear strength of saturated/unsaturated soils can be modelled by the equation proposed by Tarantino and Tombolato (2005):

$\tau=\left(\sigma-u_{w} S_{r}\right) \tan \phi$ 
where $\tau$ and $\sigma$ are the tangential and normal stress to the failure plane respectively, $u_{\mathrm{w}}$ is the pore-water pressure, $\phi$ ' is the effective 'saturated' angle of shearing resistance, and $S_{\mathrm{r}}$ is the degree of saturation.

Using the limit equilibrium method, the factor of safety FoS of the infinite slope can be calculated as follows:

FoS $=\frac{\tan \phi^{\prime}}{\tan \beta}+\frac{-u_{w} S_{x} \times \tan \phi^{\prime}}{(\bar{\gamma} H) \cdot \sin \beta \times \cos \beta}$

where $H$ is the depth of the failure surface, $\beta$ is the inclination of the slope, and $\chi$ is the average unit weight given by:

$\bar{\gamma}=\frac{1}{H} \int_{0}^{H}\left[\gamma_{s}(1-n)+\gamma_{w} n S_{r}\right] d z$

where $\gamma_{\mathrm{s}}$ and $\gamma_{\mathrm{w}}$ are the unit weight of solids and water respectively, and $n$ is the porosity.

To analyse the flow of water within the infinite unsaturated slope adopted, the two-dimensional seepage problem can be reduced to a onedimensional one by means of an axis rotation (Fig. 1). The axis rotation is developed as in Tarantino \& Mongiovì (??):

$u_{w}\left(z^{\prime}\right)=u_{w}^{*}+z^{v}(1-\cos \beta) y_{w}$

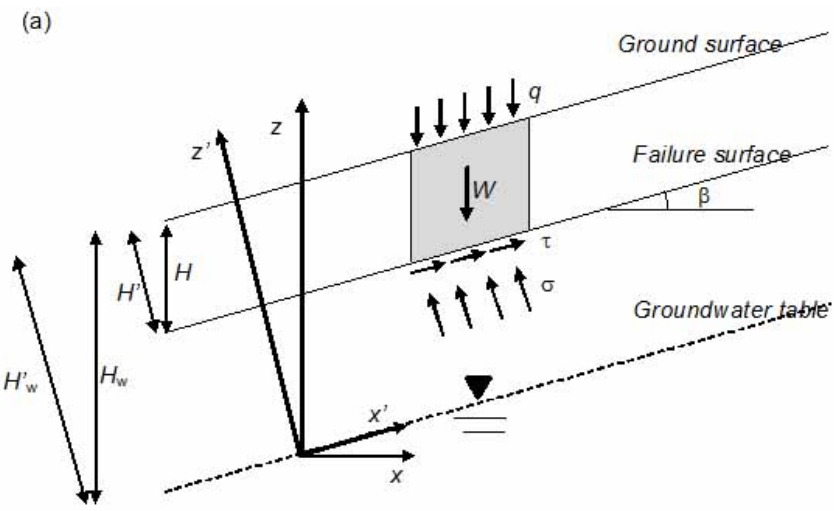

(b)

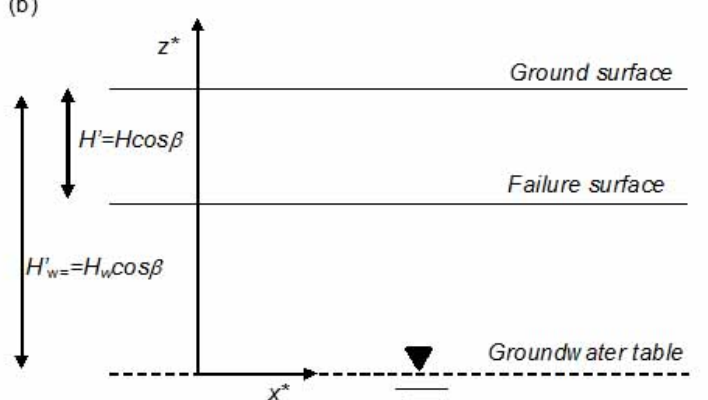

Figure 1. Infinite slope. (a) mechanical model for stability. (b) equivalent one-dimensional vertical model for water flow analysis.

\section{HYDRAULIC CHARACTERIZATION OF SOILS AND PLANT}

In order to investigate the influence of the type of soil in the analysis, two different materials have been considered: a pyroclastic silty sand and a clay.

Their hydraulic behaviour is described by the following retention and permeability curves (Fig. 2).
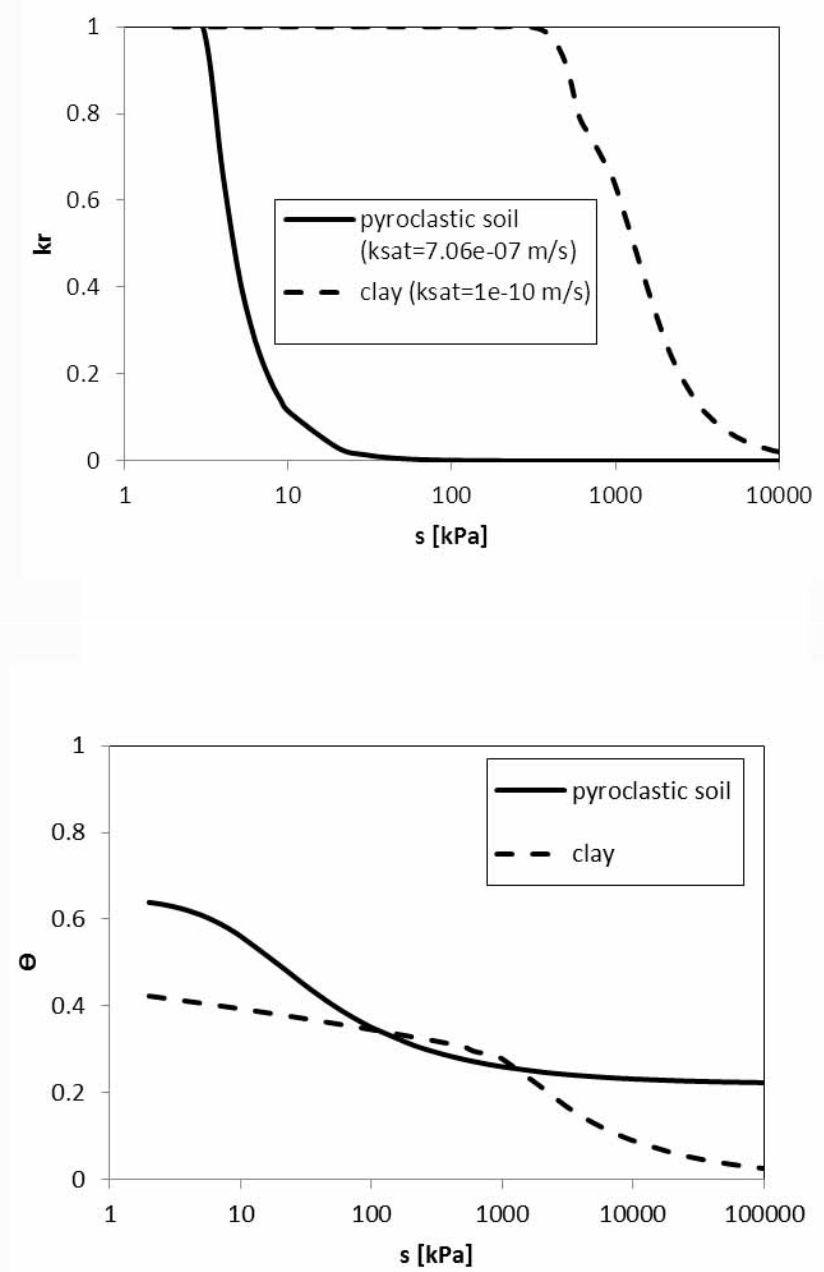

Figure 2 Hydraulic characterization: (a) relative hydraulic conductivity, (b) water content.

In order to investigate the influence of the different hydraulic properties of vegetation, different values have been adopted for the suction in the leaf and the conductivity in the xylem as shown in Table 1.

\begin{tabular}{|cc|cc|}
\hline $\begin{array}{c}\mathbf{d}_{\text {root }} \\
{[\mathbf{m m}]}\end{array}$ & $\begin{array}{c}\mathbf{i}_{\text {root }} \\
{[\mathbf{m m}]}\end{array}$ & $\begin{array}{c}\mathbf{N}_{\text {root }} \\
{\left[\mathbf{1} / \mathbf{m}^{2}\right]}\end{array}$ & $\mathbf{L}_{\mathbf{r}}[\mathbf{m}]$ \\
\hline 1 & 30 & 1000 & 1 \\
\hline \multicolumn{2}{|c|}{$\mathbf{S}_{\text {LEAF }}$} & {$[\mathbf{k P a}]$} & \multicolumn{2}{|c|}{$\mathbf{D}[\mathbf{m m} /(\mathbf{d} * \mathbf{M P a})]$} \\
\hline low & high & low & high \\
1000 & 4000 & 2 & 10 \\
\hline \multicolumn{4}{|c}{} \\
\hline
\end{tabular}


Table 1. Values of root diameter $\left(\mathrm{d}_{\text {root }}\right)$, interaxis $\left(\mathrm{i}_{\text {root }}\right)$, density $\left(\mathrm{N}_{\text {root }}\right)$ and depth $\left(\mathrm{L}_{\mathrm{r}}\right)$, suction in the leaf ( $\left.\mathrm{S}_{\mathrm{LEAF}}\right)$ and conductivity in the xylem (D).

\section{ANALYSIS AND RESULTS}

In order to understand where the limiting condition is reached between the plant and the soil, some transient analysis have been performed: a period of analysis of 30 days has been considered both for summer and winter, applying a constant flux of 5 $\mathrm{mm} /$ day and $1 \mathrm{~mm} /$ day respectively; a water table 10 $m$ depth has been considered.

In the plant, the limiting condition is given by a finite value depending on the suction in the leaf and the conductivity of the xylem as reported in the following expression:

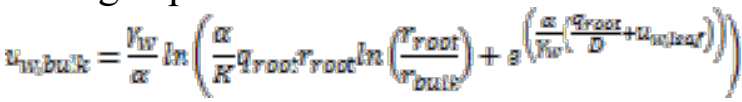

In the soil, the limiting condition is given by an infinite suction on the ground level. In a numerical analysis, in order to reproduce an infinite suction, an high but finite value for the suction has to be chosen.

At first the value of suction beyond which the software showed numerical instability issues has been chosen; this value is of $5000 \mathrm{kPa}$ for the clay and $400 \mathrm{kPa}$ for the pyroclastic soil.

These values have been comapared with the ones obtained by joining the tangents in the last point and in the maximum curvature point in a graph of suction versus time obtained by performing several transient analysis for different values of fluxes (Fig.3).
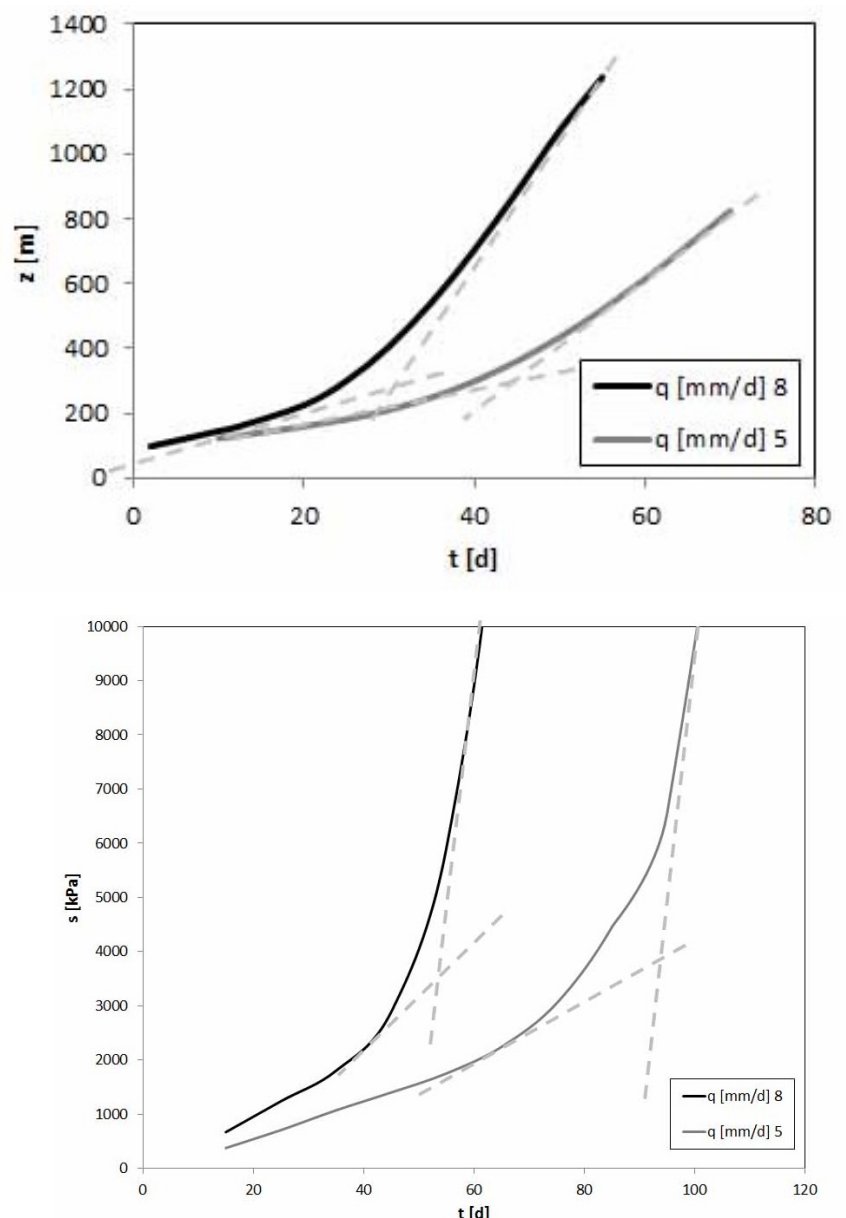

Figure 3. Finite value to reproduce the infinite suction in (a) pyroclastic soil and (b) clay.

The suction profiles obtained by imposing these values of suction are almost identical to the ones previously obtained (Fig.4); therefore the first chosen value has been adopted for all subsequent analysis.
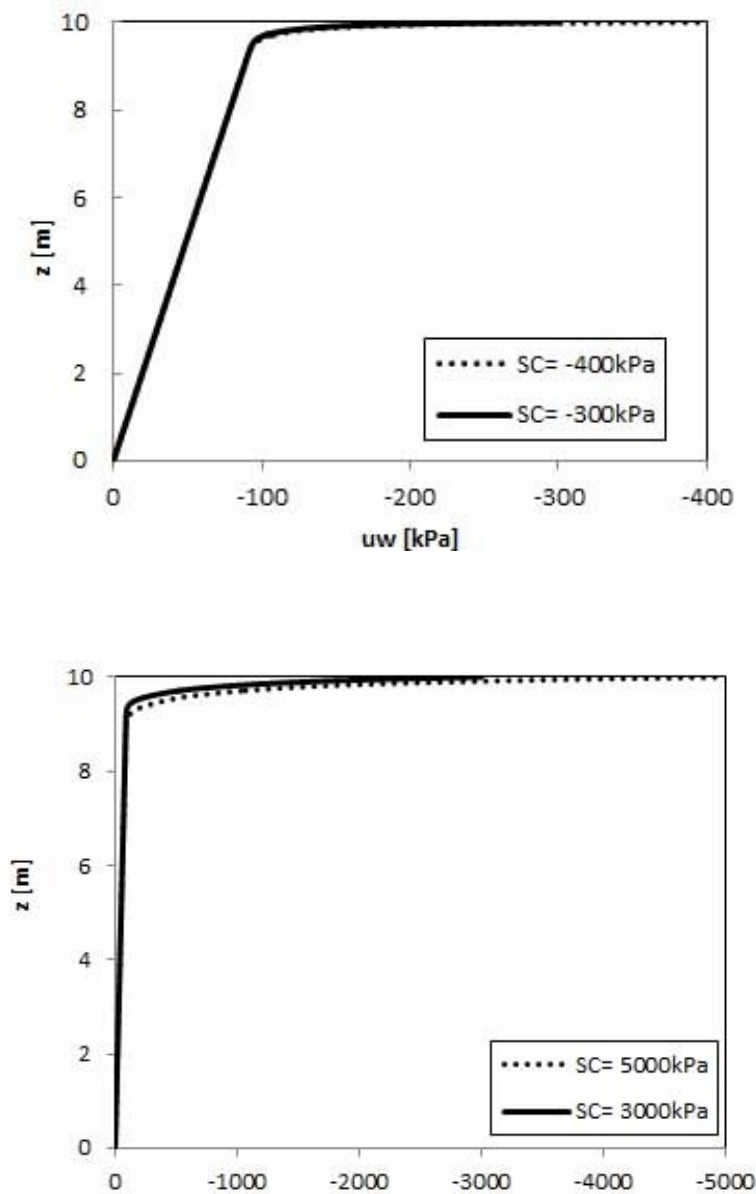

Figure 4. Comparison of the suction profiles for (a) pyroclastic soil and (b) clay.

The suction profiles obtained from the analysis are shown in Fig.5-6.

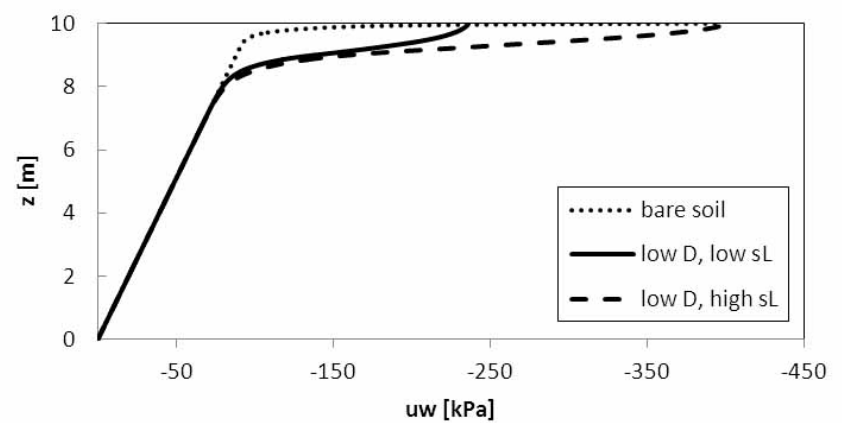




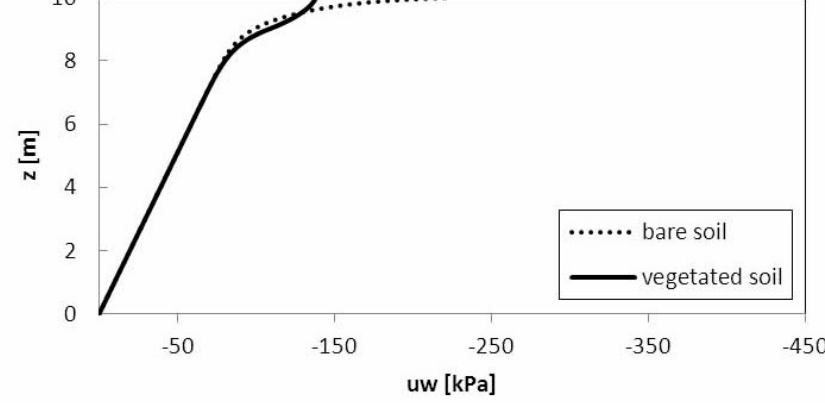

Figure 5. Suction profiles in pyroclastic soil for (a) summer and (b) winter.
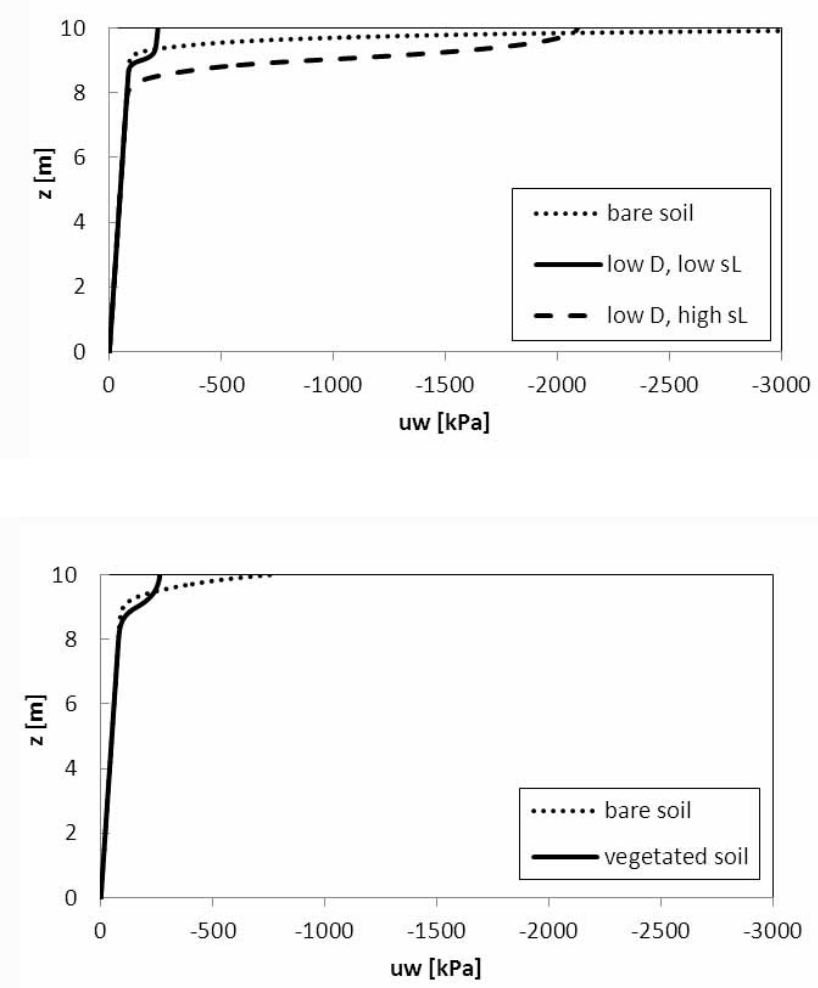

Figure 6. Suction profiles in clay for (a) summer and (b) winter.

For the winter there is not a remarkable difference between bare soil and vegetated one both for clay and pyroclastic soil.

For the summer different cases are presented. In the pyroclastic soil, when considering a low value for the suction in the leaf, the limiting condition is reached in the plant, while, when a high value of the suction in the leaf is considered, the limiting condition is reached in the soil; in the bare soil the limiting condition is reached.

In the clay, when considering a low value for the suction in the leaf, the limiting condition is reached in the plant, while, when a high value of the suction in the leaf is considered, the limiting condition is never reached; in the bare soil the limiting condition is reached.

Through expression (2), the factor of safety has been derived and the difference between the factor for the vegetated and bare soil is plotted versus depth as shown in Fig. 7-8
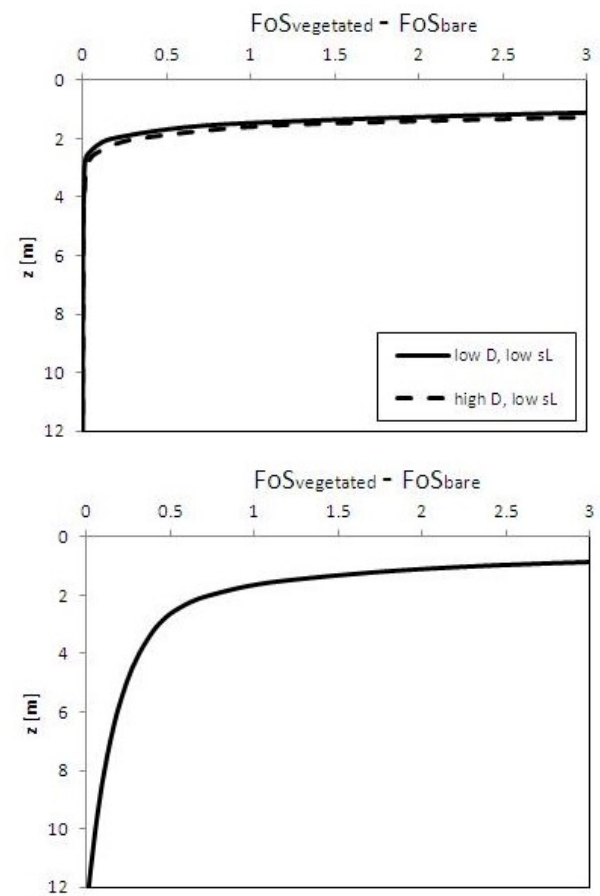

Figure 7. Factor of safety profiles in pyroclastic soil for (a) summer and (b) winter.
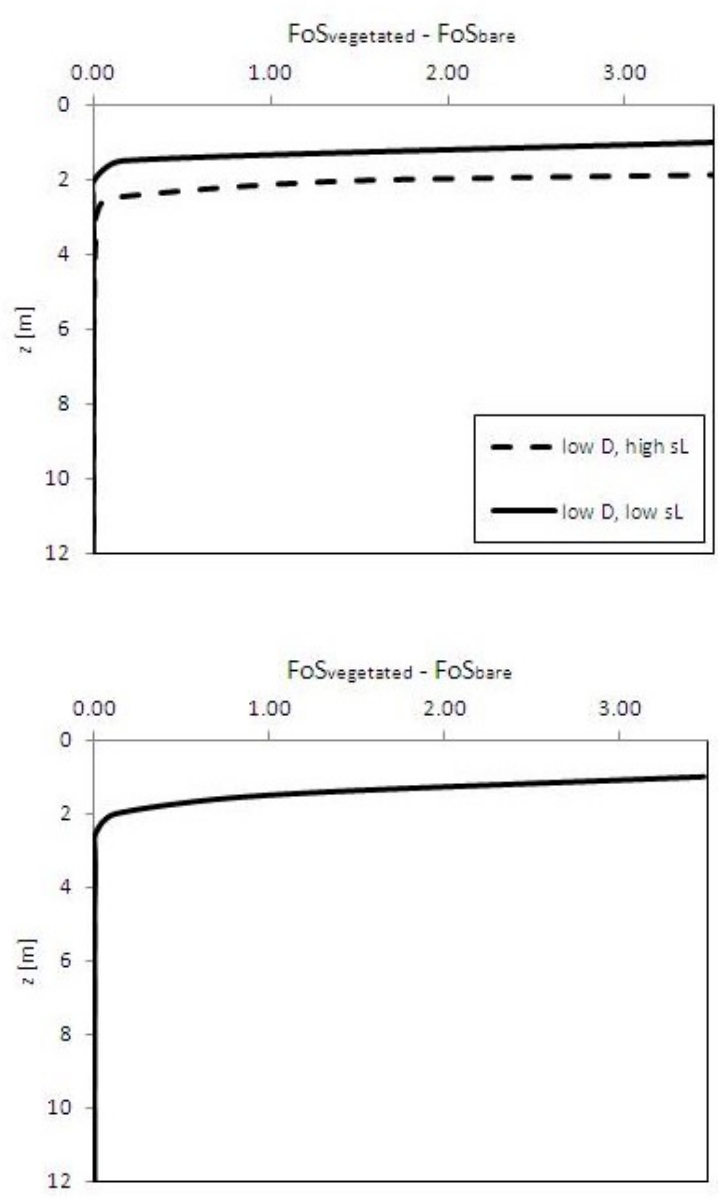

Figure 8 . Factor of safety profiles in clay for (a) summer and (b) winter. 


\section{CONCLUSION}

As shown in the previous pictures, it could be useful, for a slope stability analysis, taking into account the effects of vegetation. The vegetation contributes to an higher value of the FoS at shallow depths in all cases taken into account. Even when the limiting condition is reached in the plant, its effect is benefical for the slope stability as well. The influence of the hydraulic properties of the plant can be better seen in the clay, where, for higher value of the suction in the leaf, a greater depth is influenced by the benefical effect of vegetation.

\section{REFERENCES}

Alonso, E.E., Vaunat, J. \& Gens, A. (1999). Modelling the mechanical behaviour of expansive clay. Engineering Geology, 54: 173-183. 